\title{
Autuação e descompasso: legislação, roça e manejo florestal em assentamento ambientalmente diferenciado em Anapu, Pará
}

\section{Indictment and mismatch: environmental legislation, shifting cultivation and forest management in a land reform area in Anapu, Pará}

Laís Sousa - Mestre em Ciências Ambientais, pela Universidade Federal do Pará (UFPA). Doutoranda em Ciências Ambientais, pela Universidade Federal do Pará (UFPA). E-mail: laisvicferreira@hotmail.com

Roberto Porro - Doutor em Antropologia Cultural, pela Universidade da Flórida, Estados Unidos. Atua como pesquisador da Embrapa Amazônia Oriental. E-mail: roberto. porro@embrapa.br

\section{Resumo}

O presente artigo examina contradições entre atividades realizadas por assentados em Projeto de Desenvolvimento Sustentável em Anapu, Pará, e o disposto na legislação ambiental. A análise de impedimentos causados, tanto na agricultura tradicional como numa iniciativa de manejo florestal comunitário, identifica que os instrumentos legais existentes não contemplam práticas de subsistência específicas adotadas pelos assentados, conflitando com direitos fundamentais dos mesmos, prejudicando o bem-estar e a consolidação do assentamento de suas famílias.

\section{Palavra-chave}

Agricultura Familiar. Licenciamento Ambiental. Reforma Agrária. Transamazônica.

\begin{abstract}
This paper examines contradictions between activities carried out by settlers in a Sustainable Development Project in Anapu, Pará, and provisions of environmental legislation. Through the analysis of impediments caused both in traditional agriculture and in a communitybased forest management initiative, the study identifies that existing legal instruments do not incorporate specific forms of subsistence practiced by settlers, conflicting with their fundamental rights, and impairing their wellbeing and the consolidation of their families' settlement.
\end{abstract}

\section{Keywords}

Family Farming. Environmental Licensing. Land Reform. Transamazon. 


\section{INTRODUÇÃO}

A concentração da propriedade da terra é um dos obstáculos para o desenvolvimento de um país. Devido aos altos índices de pobreza e violência no campo, a democratização do acesso à terra é essencial, possibilitando que camponeses ${ }^{1}$ marginalizados sejam inseridos no mercado por meio da agricultura de pequena escala e alcancem meios de vida sustentáveis. A reforma agrária contribuiria, assim, para solucionar conflitos rurais mediante um conjunto de ações que visam modificar a estrutura fundiária de uma determinada região, de modo a fortalecer meios de vida de agricultores que antes não possuíam acesso à terra e gerar ganhos sociais, políticos e econômicos para o país (OLIVEIRA, 2001, p. 205).

Uma política de reforma agrária destina terras para famílias exercerem a agricultura, possibilitando a inclusão destas no mercado local, além de produzirem alimentos para consumo familiar. De acordo com Garcia Júnior (1983), nas terras ocupadas pelos chamados "pequenos produtores" predominam "lavouras de subsistência", cujos produtos são voltados ao consumo doméstico. Esta produção está diretamente ligada à manutenção do grupo familiar, que necessita do alimento produzido na lavoura.

O conceito de "lavoura de subsistência" associa-se, portanto, a direitos fundamentais necessários para a dignidade humana, devendo ser reconhecidos e materialmente efetivados (PINTO FILHO, 2002). A Declaração Universal dos Direitos Humanos inclui o direito a uma alimentação adequada, e o Estado deve intervir para garantir tais necessidades (CARVALHO, 2012). Ainda de acordo com esse autor, outros direitos fundamentais como o direito à vida e à saúde só se concretizam quando o direito à alimentação é garantido, uma vez que é a ingestão de alimentos que proporciona a energia indispensável à sobrevivência. A população no campo deve, portanto, ter acesso a recursos produtivos para, de forma adequada e soberana, produzir seu alimento e garantir sua dignidade, exercendo o direito de se alimentar (BURITY et al., 2010).

\footnotetext{
Os termos "camponês" e "agricultor familiar" são empregados neste artigo para designar os mesmos sujeitos, em consonância com o paradigma da questão agrária apresentado por Felício (2006). O uso do conceito "camponês" geralmente tem conotação associada à posição social, enquanto "agricultor familiar" reforça a forma de gestão da unidade produtiva. Marques (2008) entende o campesinato como classe social e não apenas como forma de organização da produção. A partir de definição mais restrita de campesinato, Hespanhol (2000) afirma que, a partir da década de 1990, "agricultura familiar" passa a designar unidades produtivas nas quais trabalho, produção e renda estão vinculados ao grupo familiar, substituindo categorias de análise como campesinato e pequena produção, que teriam perdido poder explicativo.
} 
Em diversas situações, contudo, camponeses em busca da produção de subsistência esbarram em legislação que regulamenta e estabelece diretrizes para utilização dos recursos naturais. Estas famílias frequentemente adotam práticas tradicionais, que por vezes as colocam em desconformidade perante leis ambientais definidas pelo Estado, que, visando à conservação, não reconhecem tais práticas e desestabilizam modos de vida.

Segundo Benatti (1998), o entendimento necessário para conhecimento e defesa do meio ambiente não deve ser restrito à flora, fauna e meio físico, sendo preciso considerar as atividades humanas. Para o autor, a Constituição Brasileira assegura o direito de equilíbrio entre elementos naturais, artificiais e culturais. Porém, na busca da proteção ambiental, a legislação muitas vezes desconsidera o fator cultural.

Com base no exposto, este trabalho enfatiza o paradoxo do conflito de direitos entre as dimensões sociais e ambientais, avaliando situações em que o direito ao meio ambiente íntegro se contrapõe ao direito fundamental de sobrevivência de agricultores familiares assentados de reforma agrária na Amazônia. O trabalho analisa situações específicas deste conflito: dispositivos legais que impedem o cultivo agrícola de subsistência e o manejo florestal comunitário, interferindo negativamente no fortalecimento dos meios de vida no Projeto de Desenvolvimento Sustentável (PDS) Virola-Jatobá, em Anapu, Pará.

A localidade em questão foi selecionada por constituir exemplo de modalidade de assentamento ambientalmente diferenciado, no qual se busca o equilíbrio entre as três dimensões do desenvolvimento sustentável. Desde o final da década de 1980, a partir de reivindicações dos seringueiros, sobretudo nos estados do Acre, Amapá e Rondônia, o governo federal estabeleceu os Projetos de Assentamento Extrativistas (PAE) como modalidade ambientalmente diferenciada de assentamento de reforma agrária². Em 1996, os PAE passam a ser definidos como Projetos de Assentamentos Agroextrativistas, cujos beneficiários são, geralmente, oriundos de comunidades tradicionais, com perfil semelhante aos residentes de unidades de conservação de uso sustentável, como Reservas Extrativistas (Resex) e Reservas de Desenvolvimento Sustentável (RDS).

Devido ao avanço no desmatamento verificado na Amazônia no final da década de 1990, restrições para criação de assentamentos convencionais em área com predominância de cobertura florestal no bioma Amazônico foram fundamentais para a criação de nova categoria de assentamento ambientalmente

\footnotetext{
Dentre os primeiros PAE instalados pelo governo federal estão o PAE Remanso (1987) e Santa Quitéria (1988), respectivamente nos municípios de Capixaba e Assis Brasil, AC (INCRA, 2020).
} 
diferenciado $^{3}$ (LE TOURNEAU; BURSZTYN, 2010). O Instituto Nacional de Colonização e Reforma Agrária (Incra) estabeleceu a categoria denominada Projeto de Desenvolvimento Sustentável (PDS) ${ }^{4}$, cuja estratégia de implementação inclui como beneficiários famílias que não necessariamente são oriundas de comunidades tradicionais residentes nas áreas objeto dos assentamentos.

A localidade selecionada, contudo, apresenta inúmeros problemas quanto à insuficiência de apoio governamental para licenciamento de atividades agrícolas e resultados negativos nas tentativas de manejo florestal ali conduzidas, resultando em insegurança no campo, elevada taxa de mobilidade e invasão por grileiros e madeireiros ilegais. A área de estudo expõe, portanto, um forte contraste entre as pretensões dos assentados, que buscam autonomia em suas atividades, e as regras e regulamentações impostas pelo Estado, que se contrapõem a tais atividades.

\section{MATERIAL E MÉTODOS}

Este artigo analisa a relação entre as formas como a legislação ambiental é aplicada, e os impactos desta em atividades realizadas por assentados do PDS

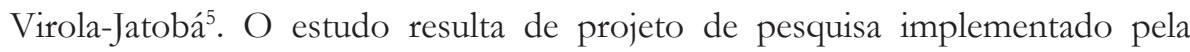
Embrapa Amazônia Oriental e Universidade Federal do Pará, em parceria com organizações locais do $\mathrm{PDS}^{6}$. A coleta de dados em campo ocorreu no período de julho a novembro de 2016, no qual foram mantidos contatos com assentados e servidores de agências governamentais com atuação no PDS Virola-Jatobá.

Localizado cerca de $25 \mathrm{~km}$ ao norte da rodovia Transamazônica e criado com base em diretrizes propostas pela missionária Dorothy Stang (1931-2005) e por movimentos sociais atuantes em Anapu, que buscavam uma opção aos assentamentos convencionais na região, a proposta do PDS apresenta-se

\footnotetext{
A Portaria no 88, de 06 de outubro de 1999, editada pelo então Ministro Extraordinário de Política Fundiária, dispõe, em seu art. 1, que "fica proibida a desapropriação, a aquisição e outras quaisquer formas de obtenção de terras rurais em áreas com cobertura florestal primária incidentes nos Ecossistemas da Floresta Amazônica, da Mata Atlântica e do Pantanal MatoGrossense e em outras áreas protegidas, assim definidas pelos órgãos federais e estaduais do meio-ambiente".

4 A Portaria/Incra/P n ${ }^{\circ} 477$, de 04 de novembro de 1999 (INCRA, 1999), estabelece que PDS é uma modalidade de Reforma Agrária que promove atividades ambientalmente diferenciadas, para grupos sociais cuja subsistência baseia-se no extrativismo e agricultura familiar, dentre outras ações de baixo impacto ambiental.

5 Criado pela Portaria/Incra/SR-01(G)/N³9/2002, de 13 de novembro de 2002 (INCRA, 2002).

6 Projeto Governança local e sustentabilidade do manejo florestal de base comunitária nos Projetos de Desenvolvimento Sustentável em Anapu, Transamazônica (Projeto Automanejo), executado com recursos da Embrapa (Código SEG 06.13.07.001.00) e Fapespa (Icaaf 104/2014).
} 
como alternativa à tendência predominante de exploração de madeira ilegal e grilagem de terras, ao mesmo tempo que apoia o direito de famílias camponesas à terra e ao reconhecimento de seus modos de vida tradicionais (GUZZO; SANTANA, 2009, p. 47).

Até meados de 2018, o PDS Virola-Jatobá possuía área total de 39.603 hectares, sendo formado por dois módulos distintos, PDS Anapu III e PDS Anapu IV. O PDS Anapu III consistia integralmente de Reserva Legal, não sendo habitado. As famílias residem numa porção do PDS Anapu IV onde se situa a Área de Uso Alternativo (AUA). Nesta, cada família é assentada numa parcela de cerca 20 hectares, onde realiza atividades de subsistência. As 160 parcelas ocupam parte de 5 glebas (128, 129, 130, 132 e 107), totalizando 3.411 hectares. O restante dos 15.083 ha do PDS Anapu IV consiste de Reserva Legal. A Portaria $\mathrm{n}^{\mathrm{Q}} 1.470$ do Incra determinou a anexação, em 31.08.2018, de mais duas glebas (177 e 180), o que permitiu a unificação do perímetro do PDS Virola-Jatobá, nome que passou oficialmente a designar o assentamento. A mesma portaria determinou a exclusão de parte das glebas 128 e 130 do PDS, de modo que a área total resultante passou a ser de 41.869 hectares (Figura 1).

Figura 1 - Localização do PDS Virola-Jatobá e das glebas que pertencem ao assentamento

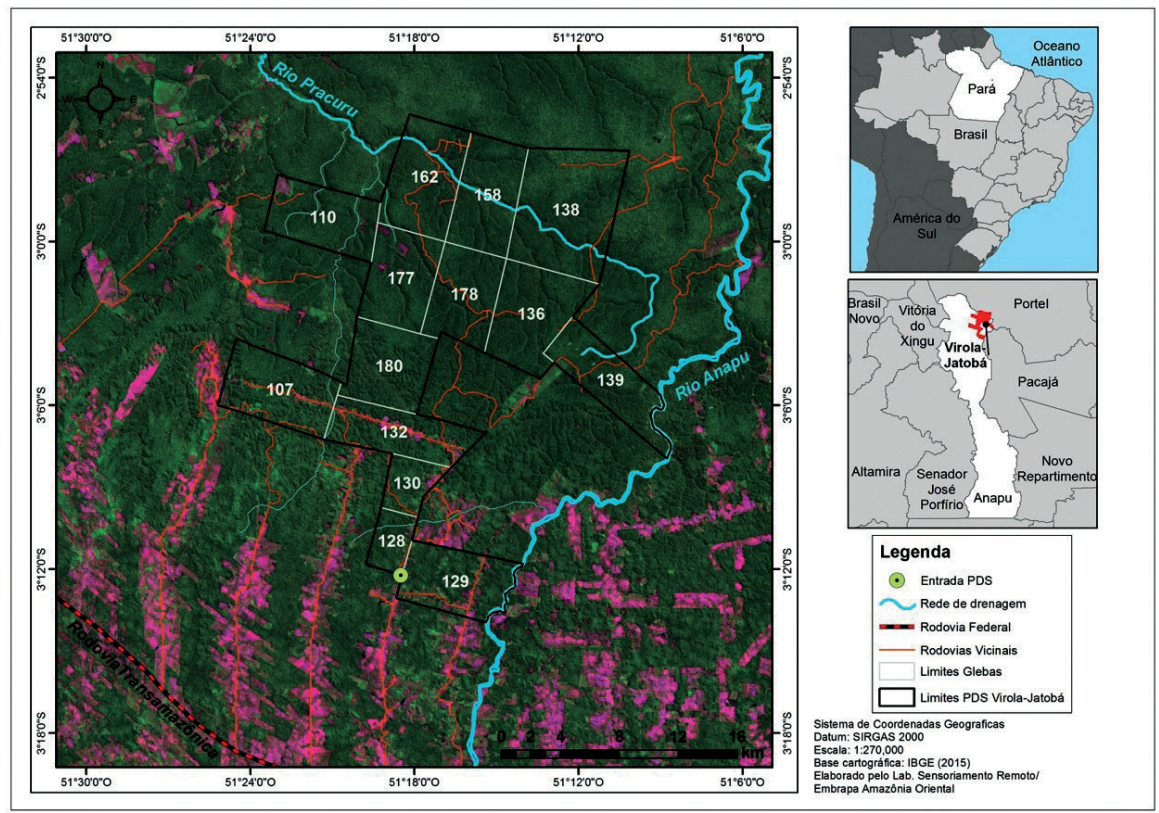

Elaboração: Frederico Elleres (2019). 
O levantamento de informações para este estudo se deu, inicialmente, por meio de coleta de dados secundários, reunindo informações sobre as famílias assentadas e residentes no PDS Virola-Jatobá, atividades por elas realizadas nos lotes, e detalhes da iniciativa de manejo florestal ali vigente desde o ano de 2008. Posteriormente, foi conduzida pesquisa de campo para realização de entrevistas com assentados e funcionários de órgãos atuantes no assentamento. Por fim, realizou-se um levantamento da legislação ambiental que impacta o assentamento, para guiar uma análise que contrasta disposições ambientais com as percepções e práticas locais.

Tendo como base o desencontro de direitos entre a legislação ambiental e a busca das famílias pelos seus meios de vida, o artigo analisa a forma como são interpretados e aplicados dispositivos legais relacionados às atividades produtivas exercidas pelos assentados no PDS Virola-Jatobá. Em especial, são focalizados dispositivos que restringem e regulam o cultivo de roças, executado individualmente pelas famílias, e o manejo florestal, executado de forma coletiva pela organização cooperativa do PDS. Assim, o artigo discute situações específicas de como a legislação vigente interfere nas atividades dos assentados, utilizando, para a análise, narrativas e discursos dos assentados em referência aos contextos apresentados.

\section{RESULTADOS E DISCUSSÃO}

\subsection{INSTRUMENTOS LEGAIS}

O Quadro 1 apresenta os principais instrumentos legais identificados como relevantes na relação com os meios de vida de famílias residentes no PDS Virola-Jatobá.

Quadro 1 - Instrumentos legais considerados nesta pesquisa

\begin{tabular}{|l|c|}
\hline Instrumento legal & Nível \\
\hline $\begin{array}{l}\text { Decreto no 2.661, de } 8 \text { de julho de 1998. Estabelece normas de precaução } \\
\text { relativas ao emprego do fogo em práticas agropastoris e florestais. } \\
\text { (BRASIL, 1998) }\end{array}$ & Federal \\
\hline $\begin{array}{l}\text { Decreto Estadual no } 1.148 \text {, de } 17 \text { de julho de 2008. Dispõe sobre o Cadastro } \\
\text { Ambiental Rural (CAR-PA) e sobre área de Reserva Legal. (PARÁ, 2008) }\end{array}$ & Estadual \\
\hline $\begin{array}{l}\text { Decreto } \mathrm{n}^{\circ} \text { 6.514, de } 22 \text { de julho de 2008. Dispõe sobre infrações e sanções } \\
\text { administrativas a quem viole regras jurídicas de uso e proteção do meio } \\
\text { ambiente, estabelece o processo administrativo federal para apuração destas } \\
\text { infrações (BRASIL, 2008). }\end{array}$ & Federal \\
\hline
\end{tabular}




\begin{tabular}{|c|c|}
\hline $\begin{array}{l}\text { Resolução CONAMA no 406, de } 02 \text { de fevereiro de } 2009 \text {. Estabelece } \\
\text { parâmetros técnicos a serem adotados na elaboração, apresentação, avaliação } \\
\text { técnica e execução de Plano de Manejo Florestal Sustentável (PMFS) com } \\
\text { fins madeireiros, para florestas nativas e suas formas de sucessão no bioma } \\
\text { Amazônia. (BRASIL, 2009a) }\end{array}$ & Federal \\
\hline $\begin{array}{l}\text { Decreto no } 6.874 \text {, de } 5 \text { de junho de 2009. Institui o Programa Federal de } \\
\text { Manejo Florestal Comunitário e Familiar (PMCF), cujo objetivo é organizar } \\
\text { ações de gestão e fomento ao manejo sustentável em florestas que sejam } \\
\text { objeto de utilização pelos agricultores familiares, assentados da reforma } \\
\text { agrária e pelos povos e comunidades tradicionais. (BRASIL, 2009b) }\end{array}$ & Federal \\
\hline $\begin{array}{l}\text { Instrução Normativa n⿳0 } 65 \text { do Incra, de } 27 \text { de dezembro de 2010. Estabelece } \\
\text { critérios e procedimentos para as atividades de Manejo Florestal Sustentável } \\
\text { em Projetos de Assentamento. (INCRA, 2010) }\end{array}$ & Federal \\
\hline $\begin{array}{l}\text { Instrução Normativa no } 3 \text { da Semas-PA, de } 13 \text { de maio de 2011. Dispõe sobre } \\
\text { a Política Estadual de Floresta e demais formações de vegetação no estado } \\
\text { do Pará. (PARÁ, 2011) }\end{array}$ & Estadual \\
\hline $\begin{array}{l}\text { Lei n }{ }^{\circ} 12.651 \text {, de } 25 \text { de maio de 2012. Estabelece normas gerais sobre a } \\
\text { proteção da vegetação, áreas de Preservação Permanente e as áreas de Reserva } \\
\text { Legal; a exploração florestal, o suprimento de matéria-prima florestal, o } \\
\text { controle da origem dos produtos florestais e o controle e prevenção dos } \\
\text { incêndios florestais, e prevê instrumentos econômicos e financeiros para o } \\
\text { alcance de seus objetivos. (BRASIL, 2012a) }\end{array}$ & Federal \\
\hline $\begin{array}{l}\text { Decreto } \mathrm{n}^{\circ} 7.830 \text {, de } 17 \text { de outubro de } 2012 \text {. Dispõe sobre o Sistema de } \\
\text { Cadastro Ambiental Rural - SICAR, sobre o Cadastro Ambiental Rural } \\
\text { (CAR), e estabelece normas de caráter geral aos Programas de Regularização } \\
\text { Ambiental (PRA). (BRASIL, 2012b) }\end{array}$ & Federal \\
\hline $\begin{array}{l}\text { Portaria no } 443 \text { do Ministério do Meio Ambiente, de } 17 \text { de dezembro de } 2014 . \\
\text { Reconhece como espécies da flora brasileira ameaçadas de extinção aquelas } \\
\text { constantes da "Lista Nacional Oficial de Espécies da Flora Ameaçadas de } \\
\text { Extinção". (BRASIL, 2014) }\end{array}$ & Federal \\
\hline $\begin{array}{l}\text { Instrução Normativa no } 08 \text { da Semas-PA, de } 25 \text { de outubro de } 2015 \text {. Define } \\
\text { procedimentos administrativos para a realização de limpeza e autorização } \\
\text { de supressão, a serem realizadas nas áreas de vegetação secundária em } \\
\text { estágio inicial de regeneração, localizadas fora da Reserva Legal e da Área de } \\
\text { Preservação Permanente (APP) dos imóveis rurais, no âmbito do estado do } \\
\text { Pará. (PARÁ, 2015) }\end{array}$ & Estadual \\
\hline
\end{tabular}

Fonte: Brasil (1998, 2008, 2009a, 2009b, 2012a, 2012b, 2014), Incra (2010) e Pará (2008, 2011 e 2015).

Elaboração: Autores (2018).

\subsection{O CULTIVO DE ROÇAS E O DIREITO À SUBSISTÊNCIA}

As famílias assentadas no PDS Virola-Jatobá buscam se estabelecer como comunidade e exercer suas atividades produtivas, diminuindo assim a dependência em relação ao Estado. Seus principais meios de vida são derivados dos cultivos 
agrícolas e da pecuária. A agricultura praticada compreende prioritariamente culturas anuais. Cultivos semiperenes, perenes e hortaliças ocorrem com menor frequência. A lavoura anual em sistema de pousio e técnica de corte-e-queima é a atividade mais comum no PDS, sendo a produção destinada tanto para consumo como para comercialização, principalmente da farinha de mandioca, vendida nas feiras e estabelecimentos comerciais de Anapu (SANTOS JÚNIOR. et al., 2017). A criação de animais de pequeno porte, principalmente galinhas e porcos, é comum no assentamento, tendo como objetivo a alimentação e geração de renda. Embora sejam poucos os lotes integralmente convertidos em pastagens, a pecuária bovina é uma atividade em expansão.

Quando o PDS foi formalmente estabelecido, em 2004, as famílias foram assentadas com base no entendimento de que poderiam utilizar para agricultura apenas os lotes na área de uso alternativo, que, em sua quase totalidade, ainda estavam cobertos de floresta. No restante da área, correspondendo a mais de $90 \%$ do território do PDS, a cobertura florestal deveria permanecer. Contudo, à época não foram formalizados acordos para que tal esquema fosse reconhecido pelos órgãos ambientais. Consequentemente, a consolidação das atividades agrícolas dos assentados, mesmo nos lotes de uso alternativo, passou a confrontar a legislação ambiental, seja por não existir autorização legal para a atividade, como pelas restrições a cultivos em áreas com cobertura florestal, principalmente após a aprovação do novo Código Florestal brasileiro, instituído mediante a Lei ํㅡำ 12.651, de 25 de maio de 2012 (BRASIL, 2012a).

O cultivo de roças é praticado por grande parte dos assentados do PDS Virola-Jatobá, sendo uma atividade tradicionalmente realizada pelo campesinato amazônico. Consiste no preparo da área por meio do broque e a derrubada das espécies arbóreas, para posterior queima e plantio. Em áreas com cobertura florestal, para que os assentados possam realizar o cultivo da roça em conformidade com a legislação, torna-se necessária uma autorização para supressão florestal (ou autorização de desmatamento), concedida pelo órgão ambiental responsável, no caso a Secretaria de Meio Ambiente e Sustentabilidade (Semas-PA), conforme disposto na Instrução Normativa Semas 3, de 13 de maio de 2011.

O Capítulo II da IN 3-2011 define os meios para supressão florestal em Projetos de Assentamento Públicos e Privados, indicando os procedimentos para a obtenção de autorização para supressão de florestas para o cultivo de roças. De acordo com a IN, é necessário apresentar ao órgão ambiental diversos documentos, entre eles: documento de criação do assentamento, a planta geral da área (com APP e RL demarcadas, além da hidrografia e coordenadas 
geográficas). É necessário apresentar também o Plano de Exploração Florestal e o Plano de Implantação da Atividade de Uso Alternativo do Solo, elaborados por engenheiro florestal e engenheiro agrônomo, respectivamente. A legislação também afirma que, em projetos de assentamento de reforma agrária, ou outros projetos públicos, a autorização deve ser encaminhada à Semas pelo órgão responsável pela gestão do assentamento.

A IN no 3-2011 da Semas-PA esclarece que a responsabilidade de viabilizar a regularização de atividades e licenças é, portanto, deste órgão responsável, e não dos assentados. Por esta razão, o Incra, como órgão gestor do assentamento, seria de fundamental importância para a adequação ambiental das atividades dos assentados. O órgão fundiário, contudo, passados mais de 15 anos desde a criação do assentamento, não viabilizou a obtenção da autorização de supressão florestal nos lotes de uso alternativo.

Quando os procedimentos para supressão não são tomados conforme recomendado pela Semas, o órgão atua de forma punitiva, por meio da fiscalização ambiental no combate à ilegalidade. ${ }^{7} \mathrm{O}$ órgão deve notificar os ocupantes que atuam de forma irregular, para que se adequem à legislação ambiental. Porém, no caso do PDS Virola-Jatobá, tal adequação deveria ter sido viabilizada pelo órgão gestor. $\mathrm{Na}$ ausência de uma iniciativa do Incra visando a regularidade ambiental para áreas de uso alternativo, os assentados têm conduzido suas atividades de forma independente, sem consultar o órgão fiscalizador, e as áreas abertas se tornam irregulares, consideradas desmatamentos ilegais. Segundo estabelece a legislação, a supressão florestal, quando autorizada e obedecendo as especificidades da legislação ambiental, é considerada atividade legal. Já o desmatamento não autorizado deve ser autuado.

De acordo com o Código Florestal de 2012, áreas desmatadas ilegalmente são passíveis de embargo. Ou seja, áreas com desmatamento não licenciado, mesmo que para cultivos de roças realizadas pelos assentados, passam a ser consideradas como embargadas, e as atividades devem ser imediatamente suspensas para que não ocorra a ampliação do dano ambiental. Por outro lado, a mesma legislação estabelece que a autuação não deveria ser aplicada quando a atividade em questão tenha como objetivo a subsistência familiar, ocasionando ambiguidades e contradições pelo órgão fiscalizador, pois o mesmo autua os assentados como causadores de desmatamento, sem considerar que este desmatamento é praticado para fins de subsistência.

O Decreto Estadual no 2.435, de 11 de agosto de 2010, estabelece e oficializa os instrumentos utilizados pelos Agentes Estaduais de Fiscalização Ambiental e os procedimentos para aplicação de sanções por infrações ambientais (PARÁ, 2010). 
Como a atividade de subsistência dos assentados foi considerada irregular pelo órgão ambiental, os mesmos estão em um impasse, entre seguir irregular e garantir seu alimento, ou paralisar suas atividades. Segundo Abramovay (1997, p. 74), o termo subsistência está ligado às necessidades de sobrevivência. Sendo assim, a agricultura de subsistência é realizada por agricultores familiares de baixa renda, em condições precárias, que utilizam técnicas tradicionais e possuem pouco acesso ao crédito rural, mas que buscam se manter na terra.

O PDS Virola-Jatobá, desde seu início, foi caracterizado por um alto índice de mobilidade dos assentados. Contribui para essa mobilidade o tratamento marginal conferido pelos órgãos ambientais à atividade agrícola tradicional, o que leva as famílias mais vulneráveis a buscarem novas áreas. Assim, não ocorre a proteção do meio ambiente, objetivo do órgão ambiental, e inviabiliza-se a reforma agrária, sob responsabilidade do Incra. A junção da ineficiência das duas instâncias resulta por somar a degradação ambiental à manutenção da pobreza no campo.

Com efeito, no PDS Virola-Jatobá, a quase totalidade da área de uso alternativo estava sob cobertura florestal no momento da chegada das famílias assentadas, e boa parte assim ainda permanecia no ano de 2008 (WATRIN; PORRO; SILVA, 2017). A antropização (desmatamento) cumulativa no PDS resultava, em julho de 2015, em cerca de 6,75\% de sua área total, ou 2.673,70 ha. A Área de Uso Alternativo (AUA) totalizava 3.411,35 hectares compreendendo os lotes de 20 hectares que podem ser destinados integralmente (com exceção das APP neles contidas) a cultivos para garantir renda e sobrevivência a cada família assentada. Deste total, 1.318,33 ha estavam antropizados em 2015, correspondendo a 38,65\% do permitido (WATRIN; PORRO; SILVA, 2017). Portanto, a suposta inconformidade com a legislação ambiental deixa de se justificar não apenas eticamente (pela necessidade de suprir o direito básico de alimentação), como também legalmente, uma vez que, em termos relativos, a área antropizada não atingia os limites estabelecidos pelo próprio Código Florestal (PORRO et al., 2018).

Em outubro de 2015, a organização representativa dos assentados, Associação Virola-Jatobá (AVJ), foi citada em auto de infração emitido pela Semas-PA, identificando desmatamentos ilegais constatados no âmbito da análise do pedido de licenciamento para manejo florestal. Observa-se que a notificação somente ocorre em 2015, referente a um período e dinâmica anterior do assentamento, durante a vigência de um acordo com empresa madeireira, 
então responsável pela exploração florestal (2008-2012) ${ }^{8}$. Caso a notificação fosse emitida logo após o Decreto n⿳0 6.514, de 22 de julho de 2008 (BRASIL, 2008), as áreas de Reserva Legal e APP notificadas seriam certamente menores, ou até mesmo nulas, já que o Incra e os assentados estariam cientes das infrações e evitariam a expansão do desmatamento.

Alguns fatores devem ser considerados, além do desmatamento em si, ao se analisar este auto de infração. A falta de ação do órgão gestor do PDS e sua desarticulação com o órgão ambiental licenciador, o nível de complexidade exigido para emissão de licenças, e o pouco conhecimento dos assentados para lidar com tais instrumentos, tornam estas famílias dependentes de agentes externos para se adequarem à legislação ambiental.

As famílias do PDS Virola-Jatobá foram, portanto, notificadas por irregularidades ambientais, sendo que a autuação não considerou que o conceito de punição por desmatamento ilegal não se aplica quando o mesmo consiste de práticas agrícolas voltadas para a subsistência. Além disso, a notificação foi destinada à associação representativa das famílias, e não ao Incra, desconsiderando a responsabilidade do órgão gestor como encarregado de definir regras para uso da terra nos lotes e viabilizar as devidas licenças ambientais para pleno funcionamento do assentamento e segurança dos assentados.

Outra dimensão, que expressa a contradição entre a legislação ambiental e as práticas tradicionais de cultivo de roças de corte-e-queima, refere-se ao enquadramento legal do período de pousio, que para o agricultor, corresponde ao "descanso" da terra previamente cultivada. O objetivo do agricultor em não utilizar a área durante um período de tempo é permitir que o solo recupere seus nutrientes (CIRNE; SOUZA, 2014). Contudo, o instrumento legal que regulariza a utilização das áreas de pousio passou também a afetar os assentados devido a divergências entre as práticas agrícolas tradicionais e a legislação. Para o Código Florestal de 2012, o conceito de pousio é associado a áreas antropizadas onde o cultivo foi interrompido por no máximo 5 anos.

A IN Semas 8, de 25 de outubro de 2015 (PARÁ, 2015), discorre sobre as práticas passíveis de autorização para remoção de vegetação secundária em

\footnotetext{
Como será detalhado na próxima seção, entre os anos 2008 e 2012 ocorreu um acordo entre a Associação Virola-Jatobá e empresa madeireira, por meio de um Plano de Manejo Florestal Comunitário com anuência do Incra. A madeira em toras era extraída pela empresa, que repassava o pagamento à associação, que por sua vez distribuía parte do valor recebido aos sócios. Devido a irregularidades relacionadas à gestão direta, por empresas, do manejo florestal em assentamentos federais, a IN-65 do Incra suspendeu o acordo no final de 2012. Em 2014, foram tomadas decisões e assumidos compromissos visando restaurar o manejo florestal no PDS com governança local dos assentados, e apoio de órgãos públicos (UFPA, Embrapa, Semas e Incra), o que efetivamente ocorreu a partir de 2016.
} 
estágio inicial de regeneração, definida como aquela resultante dos processos naturais de sucessão, após supressão total da vegetação primária por ações antrópicas ou causas naturais.

A IN estabelece processos distintos para o licenciamento destas áreas. No caso de áreas consideradas em pousio, segundo a legislação, os procedimentos referem-se à limpeza de vegetação secundária. Os documentos que devem ser apresentados são mais simples e o processo é rapidamente analisado, neste caso pelo órgão ambiental municipal, desde que o mesmo esteja habilitado. Já para o licenciamento de áreas em processo de regeneração entre 5 e 20 anos, o procedimento refere-se à autorização de supressão. As exigências são muito maiores nessas situações, incluindo, por exemplo, a necessidade de apresentação de inventário florestal da área a ser licenciada, o que torna o processo mais demorado e complexo para análise.

Em suas narrativas, os assentados do PDS consideram que um período mínimo de 8 anos de pousio é necessário para que determinada área, já cultivada, recomponha seus nutrientes para que novo roçado seja estabelecido e produza satisfatoriamente. O tempo praticado nos sistemas tradicionais utilizados no PDS para possibilitar a recuperação da capacidade de uso do solo é, portanto, superior aos 5 anos de pousio estabelecidos na legislação. Para os assentados é inviável reutilizar a área considerando períodos mais curtos de "descanso". Contudo, o licenciamento para áreas em regeneração há mais de 5 anos é complexo e vagaroso, sendo equivalente ao procedimento utilizado para obtenção de autorização de supressão em floresta primária, inviável de ser obtido a partir da iniciativa e com as condições dos assentados do PDS.

A lógica do camponês considera inviável o trabalho de estabelecer um roçado no sistema tradicional de corte-e-queima em capoeiras jovens situadas em solos pobres, como os do PDS Virola-Jatobá, devido à quantidade excessiva de ervas daninhas que demandaria uma alocação de trabalho e tornaria o resultado do cultivo antieconômico. Além disso, o volume de biomassa gerado após 5 anos não seria suficiente para recompor os nutrientes a serem fornecidos para o próximo cultivo, por meio das cinzas provenientes da queima.

Percebe-se, portanto, que as atividades dos assentados do PDS VirolaJatobá passaram a ser fortemente dirigidas pela atuação do Estado, por meio de normativas ambientais que regulam as ações do agricultor. Como resultado, o que antes eram práticas tradicionais repassadas entre gerações, hoje se estabelecem pelo que rege a legislação. De acordo com Wanderley (2003, p. 44), o agricultor familiar é um ator social da agricultura moderna, pois é resultado da atuação do Estado. A autora questiona se, a partir do momento em que o agricultor 
passa a agir com o objetivo de cumprir regulamentos exigidos pelo Estado, sua essência de camponês seria perdida. Indaga também se agricultores que seguem essa orientação constituiriam uma nova modalidade de camponês, que se forma a partir de estímulos de políticas públicas.

A legislação ambiental desconsidera as formas de uso do solo por eles utilizadas. Além do mais, pela dificuldade de acesso a tecnologias que permitam a intensificação produtiva, os mesmos acabam por realizar suas atividades à margem da legalidade, não deixando, porém, de desempenhar uma prática legítima em busca de seu direito fundamental à alimentação.

\subsection{O IMPASSE DO MANEJO FLORESTAL POR ASSENTADOS NA FRONTEIRA}

Como visto na seção anterior, os assentados do PDS Virola-Jatobá buscam estabelecer, desde 2008, uma iniciativa de manejo florestal comunitário, fator que paradoxalmente intensificou a fiscalização sobre todas as atividades ali relacionadas ao uso do solo. Neste âmbito, os assentados, por meio de sua organização representativa, foram autuados pela Semas-PA, devido à constatação de supressão florestal após julho de $2008^{9}$, sem autorização prévia do órgão ambiental, e implantação de cultivos agrícolas justamente nas áreas de uso alternativo.

O recebimento do auto de infração pela AVJ, por desmatamentos entre 2008 a 2015, ocorreu no momento em que a comunidade buscava estabelecer sua autonomia quanto à retomada do manejo florestal, pois a autorização para exploração madeireira requer integridade da floresta na área total do estabelecimento, e não apenas na área do Plano de Manejo. $\mathrm{O}$ auto de infração acentuou as inquietudes quanto ao futuro das atividades produtivas executadas pelas famílias assentadas no PDS, uma vez que as áreas autuadas passaram a estar embargadas.

Considerando as limitações da legislação ambiental para supressão florestal visando o cultivo agrícola, a integração do manejo florestal como fonte de renda adicional para os meios de vida dos assentados em Projetos de Desenvolvimento Sustentável se torna extremamente relevante. Sendo uma atividade que historicamente é associada a irregularidades e abusos, tanto para com a integridade das florestas como para com as comunidades que dela obtêm sua subsistência de modo sustentável (TORRES, 2016), o respeito à legislação ambiental é necessário para que a retirada e venda de madeira ocorram de forma criteriosa, viabilizando o benefício contínuo dos recursos florestais às gerações futuras, e assim, não

9 Data limite para anistiar infratores ambientais, estipulada pelo Código Florestal Brasileiro. 
causar empecilhos para quem executa a atividade. Porém, inúmeras dificuldades são enfrentadas para a execução do manejo florestal comunitário, dentre as quais a excessiva burocracia, a demora para a aprovação dos projetos, irregularidades na demarcação fundiária e os complexos procedimentos exigidos, que são de difícil absorção por assentados com pouca ou nenhuma experiência anterior na atividade (AZEVEDO-RAMOS; PACHECO, 2016).

O Decreto n⿳⺈ 6.874, de 5 de junho de 2009, institui o Programa Federal de Manejo Florestal Comunitário e Familiar, que tem como objetivo a geração de trabalho e renda para os beneficiários e promover o desenvolvimento sustentável pelo uso múltiplo dos recursos naturais (BRASIL, 2009). O Decreto Estadual n⿳0 11.48, de 17 de julho de 2008, define que a Reserva Legal pode ser utilizada, seguindo normativas do órgão ambiental, para extração madeireira. De acordo com esta legislação, o Plano de Manejo Florestal deve ser revisado a cada 5 anos, e a cada ano é realizado o manejo em uma unidade de produção anual (UPA) incluída em um Plano Operativo Anual (POA) a ser licenciado. O Plano de Manejo Florestal Sustentável (PMFS) é um documento que contém os procedimentos que serão utilizados para a extração madeireira, devendo atender diretrizes técnicas de caracterização do meio físico, estoque de madeira, monitoramento e desenvolvimento da floresta, entre outros pré-requisitos, normatizados pela Resolução Conama no 406, de 2 de fevereiro de 2009, a qual estabelece que, para assentamentos, o órgão ambiental licenciador é a Secretaria Estadual de Meio Ambiente.

No PDS Virola-Jatobá, a primeira tentativa de manejo florestal sustentável, com objetivo de fomentar a extração madeireira e gerar renda aos assentados, ocorreu entre 2008 e 2012, por meio de contrato com empresa privada. Porém, a partir do segundo ano, constatou-se que o contrato não havia sido respeitado pela empresa, o que gerou forte transtorno no PDS, inclusive colaborando para a elaboração da Instrução Normativa no 65 do Incra, de 27 de dezembro de 2010 (INCRA, 2010), que passa a proibir a atuação direta de empresas nas atividades de extração madeireira em assentamentos da reforma agrária a partir de dezembro de 2012, além de estabelecer que as atividades devem ser realizadas pelos assentados (caso necessário, com contratação de terceiros, para operações que demandam máquinas).

Em 2014, as lideranças do PDS propuseram o reestabelecimento do manejo florestal de acordo com o estipulado pela $\mathrm{IN} \mathrm{n}^{\circ}$ 65, ou seja, com governança local dos assentados e apoio de instituições de pesquisa e desenvolvimento. Após a resolução de pendências e eliminação de passivos do período anterior, e com o apoio financeiro do órgão gestor do assentamento, no final de 2015 efetivamente 
é obtido o licenciamento para exploração florestal, que passa a ser executada em meados de 2016. No PDS, o POA 2016 (UPA 6) compreendeu uma área de 545 hectares. Todas as atividades que não requerem o uso de tratores são realizadas pelos próprios assentados, organizados em sua cooperativa, de acordo com planos de trabalho para cada etapa. Por ser o primeiro ano desta modalidade de gestão, os assentados manejadores demandaram constante assessoria técnica especializada, além de capacitação contínua, visando gradualmente viabilizar o controle pelos próprios beneficiários dos processos envolvidos. Para tanto, um engenheiro florestal prestou serviços em tempo integral à organização comunitária, assumindo a responsabilidade técnica pelo Plano de Manejo Florestal, enquanto outros especialistas contribuíram com capacitações específicas.

Uma das principais dificuldades observadas para a execução do manejo comunitário no PDS é a falta de entendimento dos assentados quanto às exigências e às normas legais definidas para a extração madeireira com objetivo de produção econômica e impactos reduzidos. Como exemplo, os manejadores, por vezes, ainda têm dificuldade em excluir da relação de árvores selecionadas para corte algumas que, apesar de apresentarem elevado potencial econômico, estão localizadas em áreas cujo acesso ou topografia tornaria a exploração inviável. Devido à prática convencional, o corte nem sempre é realizado em conformidade com a orientação técnica, causando perdas na quantidade de madeira. Dificuldades ainda maiores ocorrem na adoção dos procedimentos de cubagem e romaneio das toras, que devem ser inseridos em sistema informatizado disponibilizado pela Semas e cuja operacionalização prática ainda não é completamente assimilada.

A dependência gera insegurança na execução das atividades, assim como problemas na gestão do empreendimento, tanto na regularidade dos procedimentos de campo quanto no processo de valoração e comercialização dos produtos gerados.

De fato, a condução do manejo florestal implica em atender uma série de exigências contidas na Resolução Conama no 406, de 02 de fevereiro de 2009, que estabelece parâmetros técnicos para planos de manejo florestal. Porém, no caso de um plano de manejo florestal executado em área de reforma agrária administrada pelo governo federal, algumas ações fogem ao papel dos assentados ou mesmo de eventuais terceirizados, como é o caso da regularidade da demarcação topográfica e georreferenciamento da área, assim como a definição do perímetro de lotes e áreas comuns, que são requeridas no processo de licenciamento, mas são atribuição do Incra.

Para aprovação do POA, em 2015, o órgão ambiental notificou o Incra, exigindo atualização nos registros no Cadastro Ambiental Rural (CAR) 
do PDS, que estavam defasados, assim como um relatório referente ao georreferenciamento da área. $\mathrm{O}$ acordo entre os dois órgãos estabeleceu que o documento seria enviado antes do ciclo seguinte. Passados 5 anos, tal processo permanece inconcluso. O CAR é um instrumento utilizado para direcionar a recuperação de áreas degradadas e a conservação de recursos naturais, auxiliando o processo de regularização das propriedades rurais baseado em informações georreferenciadas, com a delimitação das áreas de Reserva Legal e Áreas de Preservação Permanente.

Contudo, além da dificuldade em atualização dos registros do PDS no CAR, o instrumento, por ser declaratório e não necessitar de confirmação quando apresentado aos órgãos ambientais, está sendo indevidamente utilizado. Grileiros e terceiros que deles adquirem ilegalmente terras declaram registros falsos, seja em sobreposição à área do PDS, ou em terras devolutas a ela adjacentes, com objetivos de tomar posse de forma irregular e comercializar terras da União, problemática que interfere diretamente nas atividades de manejo florestal e na integridade do assentamento, em constante ameaça de invasão.

Durante o período em que o manejo florestal havia sido realizado pelo acordo com empresa madeireira, entre 2008 e 2012, o Plano de Manejo utilizou um pátio principal para estocagem de madeira nas proximidades dos lotes de moradia do PDS Anapu IV. Naquele período, algumas UPAs para exploração madeireira localizavam-se nesta parte do PDS. Todavia, a partir de 2016, a exploração florestal passou a ser permitida somente no então PDS Anapu III, pois a legislação define que uma Autorização para Exploração Florestal (Autef) seja vinculada somente a um registro no Cadastro Ambiental Rural. Como consequência, a Semas-PA vedou a utilização do pátio já estabelecido em 2008, vinculado ao CAR do PDS Anapu IV, e demandou a abertura de novo pátio. Ou seja, resultou dessa situação o desmatamento desnecessário, em área do então PDS Anapu III, ao qual a Autef do Plano de Manejo passou a ser associada.

Este exemplo evidencia a falta de sintonia entre órgãos e instrumentos vinculados à aplicação da legislação ambiental em Planos de Manejo Florestal em assentamentos. Enquanto o órgão gestor do PDS não oferece o amparo necessário para que se executem atividades sustentáveis e de baixo impacto, o órgão ambiental se depara com contradições entre os instrumentos para licenciamento ambiental do manejo florestal, causando inclusive danos ambientais desnecessários.

Por sua dimensão, as terras do PDS são constantemente invadidas por terceiros, que buscam a exploração madeireira ilegal. Os próprios assentados relatam as diversas vezes que presenciaram a invasão do PDS Virola-Jatobá. 
Dentre estas, em julho de 2016, quando realizavam atividades do manejo florestal, os assentados constataram a abertura de picadas na floresta. No local desta abertura, a equipe de manejadores já havia demarcado árvores selecionadas para a colheita florestal de 2016. A picada adentrava as terras do PDS exatamente onde se localizava o marco de concreto georreferenciado pelo Incra. Outro acontecimento semelhante deu-se quando pessoas estranhas ao assentamento praticavam a marcação de árvores para futura extração ilegal. As ações ilegais foram notadas por assentados durante atividades de treinamento, necessárias ao manejo, o que demonstra claramente a vulnerabilidade da área, tanto para os assentados, quanto para o meio ambiente.

Outro fator que interferiu na execução do manejo florestal do PDS VirolaJatobá foi a Portaria 443 do Ministério do Meio Ambiente, de 17 de dezembro de 2014 (BRASIL, 2014), que incluiu a espécie acapu (Vonacapona americana Aubl.) na lista das espécies ameaçadas. De acordo com a portaria, o acapu está em perigo, sendo vedada sua extração e inclusão em planos de manejo florestal. Ocorre, porém, que nas florestas de Anapu e região, a espécie é tradicionalmente reconhecida como uma das mais abundantes, sendo frequentemente demandada por fazendeiros como matéria-prima para confecção de estacas para cercar pastagens. A proibição da exploração do acapu causou efeito inverso, isto porque, as áreas do PDS Virola-Jatobá têm sido constantemente invadidas para extração ilegal da espécie, causando danos ambientais e acentuando a problemática social ao beneficiar os extratores ilegais.

Tal proibição causa também forte impacto econômico, pois com base nesta Portaria, o manejo florestal do PDS fica comprometido. A espécie de maior abundância nas áreas de exploração, de acordo com inventário realizado, é exatamente o acapu, possuindo a maior densidade de árvores, maior dominância e maior frequência, não podendo, porém, ser incluída no POA. Com base nesta contextualização, foi solicitado à Semas que o Plano de Manejo do PDS Virola-Jatobá se tornasse área piloto para exploração de acapu, possibilitando a manutenção da floresta, uma vez que a exploração seguiria os passos do manejo florestal com impacto reduzido, garantindo a conservação da espécie, sem interferir nos valores que poderão ser legalmente arrecadados pelos assentados com a espécie manejada, e inibindo também a ação de invasores e reafirmando a defesa do território e dos recursos. Protocolado na Semas em 2016, tal processo ainda não recebeu aprovação dos órgãos ambientais.

Benatti (2003) já afirmava que um dos fatores da falta de sucesso de manejo florestal comunitário consiste no fato de os comunitários não estarem 
efetivamente inseridos em todas as atividades. No PDS Virola-Jatobá, a realidade não é diferente. O planejamento e execução das atividades mais complexas ainda demandam assessorias externas, haja vista que problemas de interação entre o próprio grupo difundem informações equivocadas. Por ainda não ser executado de forma autônoma pelos próprios assentados, a realização do gerenciamento do manejo dificulta as etapas da exploração florestal, influenciando até o processo de comercialização dos produtos gerados.

Ademais, o órgão responsável pelo assentamento não cumpre as exigências propostas desde a criação do mesmo. Isso inclui a falta de apoio técnico para os assentados, a demora para o reconhecimento dos beneficiários da reforma agrária e a dificuldade para assentados acessarem créditos de apoio a que têm direito. Além dessas questões, essenciais para o sucesso do assentamento e para assegurar a permanência do assentado no lote, o Incra não consegue cumprir acordos que afetam a regularidade do manejo florestal, como a atualização do Cadastro Ambiental da área, o que expõe o assentamento a invasões.

\section{CONSIDERAÇÕES FINAIS}

As atividades agrícolas e florestais em assentamentos ambientalmente diferenciados na Amazônia, como o PDS Virola-Jatobá, estão sujeitas e devem se adequar à legislação ambiental nos níveis estadual e federal. Porém, considerando o direito fundamental à alimentação para as famílias residentes no campo, é necessário considerar as peculiaridades locais e as dificuldades enfrentadas, de forma a viabilizar uma gradual adoção do disposto na legislação. Para as atividades rotineiras da roça que produz alimentos para o sustento familiar, os assentados utilizam tecnologias tradicionais, que mesmo assim necessitam de adequação e autorização para serem realizadas. É o caso da supressão florestal, a queima, e mesmo a prática do pousio. Necessita-se, portanto, de procedimentos que, enquanto criteriosos no estabelecimento de limites, sejam passíveis de adoção, considerando as particularidades dos agricultores familiares em áreas de fronteira.

Como proposta para a solução desse impasse, no caso particular de assentamentos da modalidade PDS, sugere-se inicialmente a efetivação da função das Áreas de Uso Alternativo (AUA), conforme zoneamento definido para os PDS. Tal se daria por meio de avaliação criteriosa da cobertura da terra e classificação ambiental destas áreas, que deve ser realizada de forma expedita pelo Incra. Nesse sentido, os órgãos ambientais reconheceriam a conformidade de AUA antropizadas até o marco temporal a ser estabelecido 
para a análise, desde que excluídas as Áreas de Preservação Permanente (APP). Em AUA antropizadas que incidem sobre APP, sugere-se a gradual recuperação das mesmas em prazo de até 5 anos, por meio de Termos de Ajustamento de Conduta (TAC) individuais, a serem celebrados entre o órgão ambiental e os assentados, com aval da associação.

Assim, a partir da data em que forem estabelecidos os acordos, futuras solicitações de supressão florestal na AUA devem ser submetidas apenas para áreas onde não incidam APPs, utilizando-se formulário adaptado, específico à condição de produtor assentado, a ser elaborado para esta finalidade, sendo estabelecido o limite máximo de 3 hectares/ano/família, e possibilidade de comercialização de créditos de madeira mediante apresentação de inventário florestal que assegure a cadeia de custódia das espécies comerciais ali existentes.

No PDS Virola-Jatobá, a busca por alternativas econômicas pelos assentados levou ao reestabelecimento do manejo florestal na reserva legal, após uma primeira iniciativa ter sido suspensa por irregularidades da empresa que a executava. Na condução do manejo florestal com governança local, novamente várias problemáticas relacionadas ao licenciamento e legislação ambiental foram observadas. Azevedo-Ramos e Pacheco (2016) afirmam não ser possível o Estado, na busca de maior controle, criar regras sem condições de serem cumpridas e nem exigir que potenciais beneficiários de atividades econômicas as cumpram. Resulta o fortalecimento de atividades ilegais e o enfraquecimento dos produtores pautados pela legalidade. Como visto neste estudo de caso, os desafios que envolvem o PDS Virola-Jatobá expressam a fragilidade dos assentados em manterem sua existência com atividades de subsistência. Expressam também a fragilidade da própria legislação, em não viabilizar instrumentos e medidas que possam se adequar à realidade sociocultural de indivíduos que necessitam manter suas atividades para terem contemplados seus direitos fundamentais.

O objetivo deste artigo não é propor uma legislação mais flexível, mas sim apresentar as especificidades da categoria de assentados em PDS que enfrenta dificuldades nas relações com os órgãos ambientais. Em particular, no que se refere às regras para o licenciamento e gestão florestal, urge implementar políticas que contemplem necessidades específicas de planos de manejo florestal de caráter comunitário e/ou familiar, com ênfase no reconhecimento e garantia dos direitos (territoriais, sociais, ambientais, econômicos e culturais) das comunidades e dos agricultores familiares, com respeito e valorização às suas identidades, formas de organização e instituições. Tais políticas devem incluir eixos direcionados à gestão ambiental, formação e treinamento, fomento 
e financiamento, fortalecimento de cadeias produtivas, e especial atenção para a relação das comunidades locais com prestadores de serviços florestais e compradores de bens, serviços e produtos florestais ${ }^{10}$.

Sobretudo, é preciso reafirmar a necessidade de interação entre órgãos públicos que atuam em assentamentos ambientalmente diferenciados, para que possam ser alcançados os princípios propostos a essa modalidade de assentamento: o desenvolvimento social e econômico e a conservação ambiental. A manutenção das condições atualmente vigentes não apresenta benefício para nenhum dos envolvidos: os assentados seguem realizando atividades de forma irregular e acusam órgãos públicos como omissos e responsáveis pela inviabilização de seus meios de vida, declinando em realizar as atividades recomendadas. Por outro lado, os órgãos ambientais não obtêm sucesso na redução do desmatamento, realizando atividades repetitivas e ineficientes na proteção ambiental. Por seu turno, órgãos fundiários e demais agências governamentais não viabilizam a efetiva consolidação dos assentamentos, promovendo resultados contrários a seus objetivos, quais sejam: a reconcentração da posse da terra e o recrudescimento dos conflitos no campo.

\section{REFERÊNCIAS}

ABRAmOVAY, R. Agricultura familiar e uso do solo. São Paulo em Perspectiva, São Paulo, v. 11, n. 2, p. 73-78, 1997. Disponível em: http:// produtos.seade.gov. br/produtos/spp/v11n02/v11n02_08.pdf. Acesso em: 20 dez. 2018.

AZEVEDO-RAMOS, C.; PACHECO, J. Economia florestal comunitária e familiar na Amazônia. In: PEZUTTI, J.; AZEVEDO-RAMOS, C. (org.). Desafios amazônicos. Belém: NAEA, 2016. p. 357-396.

BENATTI, J. H. A Criação de unidades de conservação em áreas de apossamento de populações tradicionais um problema agrário ou ambiental? Novos Cadernos NAEA, Belém, v. 1, n 2, p. 1-14, 1998 Disponível em: http://www.repositorio. ufpa.br/jspui/bitstream/2011/3076/1/Artigo_CriacaoUnidadesConservacao. pdf. Acesso em: 3 nov. 2018.

BENATTI, J. H. Posse agroecológica e manejo florestal: à luz da Lei 9.985/00. Curitiba: Editora Juruá, 2003. 236p.

10 No estado do Pará, permanece em análise a minuta do decreto de criação da Política Estadual de Manejo Florestal Comunitário e Familiar, elaborada a partir de processo participativo iniciado ainda em 2012, conduzido pelo Instituto de Desenvolvimento Florestal e da Biodiversidade do Pará (Ideflor-Bio). 
BRASIL. Decreto n² 2.661, de 8 de julho de 1998. Regulamenta o parágrafo único do art. 27 da Lei no 4.771, de 15 de setembro de 1965 (código florestal), mediante o estabelecimento de normas de precaução relativas ao emprego do fogo em práticas agropastoris e florestais, e dá outras providências. Diário Oficial da União, Brasília, 09 jul. 1998.

BRASIL. Decreto nº 6.514 de 22 de julho de 2008. Dispõe sobre as infrações e sanções administrativas ao meio ambiente, estabelece o processo administrativo federal para apuração destas infrações, e dá outras providências. Diário Oficial da União, Brasília, 23 jul. 2008.

BRASIL. Decreto nำ 6.874, de 5 de junho de 2009. Institui, no âmbito dos Ministérios do Meio Ambiente e do Desenvolvimento Agrário, o Programa Federal de Manejo Florestal Comunitário e Familiar - PMCF, e dá outras providências. Diário Oficial da União, Brasília, 08 jul. 2009a.

BRASIL. Resolução n⿳ำ 406, de 2 de fevereiro de 2009. Estabelece parâmetros técnicos a serem adotados na elaboração, apresentação, avaliação técnica e execução de Plano de Manejo Florestal Sustentável-PMFS com fins madeireiros, para florestas ativas e suas formas de sucessão no bioma Amazônia. Diário Oficial da União, Brasília, 06 fev. 2009b.

BRASIL. Lei $n^{\circ}$ 12.651, de 25 de maio de 2012. Dispõe sobre a proteção da vegetação nativa; altera as Leis nํㅜ 6.938, de 31 de agosto de 1981, 9.393, de 19 de dezembro de 1996, e 11.428, de 22 de dezembro de 2006; revoga as Leis $n^{\circ}$ 4.771, de 15 de setembro de 1965, e 7.754, de 14 de abril de 1989, e a Medida Provisória $\mathrm{n}^{\mathrm{o}}$ 2.166-67, de 24 de agosto de 2001; e dá outras providências. Diário Oficial da União, Brasília, 28 abr. 2012a.

BRASIL. Decreto nº 7.830, de 17 de outubro de 2012. Dispõe sobre o Sistema de Cadastro Ambiental Rural, o Cadastro Ambiental Rural, estabelece normas de caráter geral aos Programas de Regularização Ambiental, de que trata a Lei $\mathrm{n}^{\circ}$ 12.651, de 25 de maio de 2012, e dá outras providências. Diário Oficial da União, Brasília, 17 ago. 2012b.

BRASIL. Ministério do Meio Ambiente. Portaria 443 do Ministério do Meio Ambiente, de 17 de dezembro de 2014. Diário Oficial da União, Brasília, 18 dez. 2014.

BURITY, V.; FRANCESCHINI, T.; VALENTE, F.; RECINE, E.; LEÃO, M.; CARVALHO, M. F. Direito humano à alimentação adequada no contexto da segurança alimentar e nutricional. Brasília, DF: ABRANDH, 2010. 204p. 
CARVALHO, O. F. O direito fundamental à alimentação e sua proteção jurídico internacional. Revista De Direito Público, Londrina, v. 7, n. 2, p. 181-224, 2012. Disponível em: http://www.uel.br/revistas/uel/index.php/direitopub/ article/viewFile/11174/11280. Acesso em: 22 jan. 2019.

CIRNE, M. B.; SOUZA, A. G. S. M. Pousio: o que é e quais são os seus possíveis reflexos nas questões ambientais. Veredas do Direito, Belo Horizonte, v. 11, n. 21, p. 75-106, 2014. Disponível em: http://www.domhelder.edu.br/revista/ index.php/veredas/article/view/311/400. Acesso em: 8 set. 2018.

FELÍCIO, M. J. Os camponeses, os agricultores familiares: paradigmas em questão. Geografia, Londrina, v. 15, n. 1, p. 205-219, jan./jun. 2006. Disponível em: http://www.uel.br/revistas/uel/index.php/geografia/article/ viewFile/6661/6012. Acesso em: 23 fev. 2020.

GARCIA JÚNIOR., A. Terra de trabalho: trabalho familiar e pequenos agricultores. Rio de Janeiro: Paz e Terra, 1983. 120p.

GUZZO, M. R. S.; SANTANA, N. S. Irmã Dorothy Stang - a mártir do PDS. Anapu: [s. n.], 2009. Mimeografado.

HESPANHOL, R. A. M. Produção familiar: perspectivas de análise e inserção na microregião geográfica de Presidente Prudente. 2000. 357 f. Tese (Doutorado em Geografia) - Instituto de Geociências e Ciências Exatas, Universidade Estadual Paulista, Rio Claro, 2000.

INCRA. Portaria no 477, de 04 de novembro de 1999. Trata da criação de Projeto de Desenvolvimento Sustentável. Brasília: INCRA, [1999]. Disponível em: http://www.incra.gov.br/sites/default/files/uploads/institucionall/legislacao--/ portarias/portarias-de-1999/portaria_incra_p477_041199.pdf. Acesso em: 16 out. 2015.

INCRA. Portaria/INCRA/SR-01(G) no 39/2002, de 13 de novembro de 2002. Trata da criação de Projeto de Desenvolvimento Sustentável Virola-Jatobá. Brasília: INCRA, [2002]. Disponível em: http://portal.incra.gov.br/sites/ default/files/uploads/institucionall/legislacao--/portarias/portarias-de-2002/ portaria_incra_p39_131102.pdf. Acesso em: 16 out. 2015.

INCRA. Instrução Normativa n⿳o 65 de 27 de dezembro de 2010. Estabelece critérios e procedimentos para as atividades de Manejo Florestal Sustentável em Projetos de Assentamento. Brasília: INCRA, [2010]. Disponível em: http:/ /www. incra.gov.br/tree/info/file/2562. Acesso em: 15 out. 2015. 
INCRA. Projetos de Reforma Agrária conforme fases de implementação. Brasília: INCRA, 2020. Disponível em: http://www.incra.gov.br/sites/default/ files/uploads/reforma-agraria/questao-agraria/reforma-agraria/projetos_ criados-geral.pdf. Acesso em: 24 fev. 2020.

LE TOURNEAU, F. M.; BURSZTYN, B.; Assentamentos Rurais na Amazônia: contradições entre a política agrária e a política ambiental. Ambiente \& Sociedade, Campinas, v. 13, n. 1, p. 111-130, 2010. Disponível em: http:/ /www. scielo.br/pdf/asoc/v13n1/v13n1a08.pdf. Acesso em: 24 fev. 2020.

MARQUES, M. I. M. A atualidade do uso do conceito de camponês. Revista Nera, Presidente Prudente, ano 11, n. 12, p. 57-67, jan./jun. 2008.

OLIVEIRA, A. U.; A longa marcha do campesinato brasileiro: movimentos sociais, conflitos e Reforma Agrária. Estudos Avançados, São Paulo, v. 15, n. 43, p. 185-206, 2001. Disponível em: http://dx.doi.org/10.1590/S010340142001000300015. Acesso em: 12 jan. 2019.

PARÁ. Decreto Estadual n⿳ 1.148, de 17 de junho de 2008. Dispõe sobre o Cadastro Ambiental Rural - CAR-PA, área de Reserva Legal e dá outras providências. Diário Oficial do Estado do Pará, Belém, 17 jul. 2011.

PARÁ. Decreto Estadual n 2.435, de 11 de agosto de 2010. Estabelece e oficializa os Instrumentos de Fiscalização Ambiental utilizados pelos Agentes Estaduais de Fiscalização Ambiental e os procedimentos para aplicação de sanções por infrações ambientais. Diário Oficial do Estado do Pará, Belém, 11 ago. 2010.

PARÁ. Secretaria de Estado de Meio Ambiente e Sustentabilidade. Instrução Normativa $\mathrm{n}^{\mathrm{o}}$ 3, de 13 de maio de 2011. Dispõe sobre a Política Estadual de Floresta e demais formações de vegetação no Estado do Pará, e dá outras providências. Diário Oficial do Estado do Pará, Belém, 13 maio 2011.

PARÁ. Instrução Normativa $n^{\circ}$ 08, de 28 de outubro de 2015. Define procedimentos administrativos para a realização de limpeza e autorização de supressão, a serem realizadas nas áreas de vegetação secundária em estágio inicial de regeneração, localizadas fora da Reserva Legal e da Área de Preservação Permanente - APP dos imóveis rurais, no âmbito do Estado do Pará, e dá outras providências. Diário Oficial do Estado do Pará, Belém, n. 33.003, 28 out. 2015. PINTO FILHO, F. B. M. A intervenção federal e o federalismo Brasileiro. Rio de Janeiro: Forense, 2002. 
PORRO, R.; PORRO, N. S. M., WATRIN, O.; SANTOS JÚNIOR., C. F.; MAGALHÃES, H. N. Mobilidade, renda e desmatamento: diversidade e resiliência do campesinato em assentamento com ênfase ambiental em Anapu, Amazônia Oriental. Revista de Economia e Sociologia Rural, Piracicaba, v. 56, n. 4, p. 623-644, 2018.

SANTOS JÚNIOR., C. F.; SÁ, T. D. A.; PORRO, N. S. M.; PORRO, R. Segurança alimentar em assentamentos com ênfase ambiental: um estudo de caso do PDS Virola-Jatobá, Transamazônica, Pará, Brasil. Sustentabilidade em Debate, Brasília, v. 8, n. 1, p. 54-66, 2017. Disponível em: http://periodicos.unb.br/index. php/sust/article/view/21598. Acesso em: 20 set. 2018.

TORRES, M. Os assentamentos fantasmas e a metafísica da reforma agrária: análise da relação entre o Incra no oeste paraense, a extração ilegal de madeira e os números do II PNRA. GEOgraphia, Niterói: UFF, v. 18, n. 37, p. 205-232, 2016. Disponível em: http://periodicos.uff.br/geographia/article/view/13765. Acesso em: 7 jul. 2018.

WANDERLEY, M. N. B. Agricultura familiar e campesinato: rupturas e continuidade. Estudos Sociedade e Agricultura, Rio de Janeiro, v. 21, p. 42-61, 2003. Disponível em: https://wp.ufpel.edu.br/leaa/files/2014/06/Texto-6.pdf. Acesso em: 15 ago. 2018.

WATRIN, O.; PORRO, R.; SILVA, T. M. Desflorestamento e mobilidade em lotes de projeto de desenvolvimento sustentável em Anapu, Pará. Geografia, Rio Claro, v. 42, n. 1, p. 57-69, 2017. 